\title{
The Copenhagen Conference: Quantum Limits of Knowledge
}

\author{
Eugene S. Polzik
}

Published online: 13 May 2020

(C) Chapman University 2020

The papers presented in this Special Issue elaborate on the talks that their authors presented at the conference "Quantum Limits of Knowledge" conducted at the Niels Bohr Institute in Copenhagen in June 2019. The conference generously supported by John Templeton Foundation as part of the grant "Quantum Limits of the Measurement of Motion" collected an outstanding group of speakers addressing big questions at the borderline between physics and philosophy.

This special issue would not have been possible without the relentless efforts of Dr. Andrew Jordan to overcome the usual laziness of invited speakers towards writing up papers based on their talks. The result, for which Andrew deserves a lot of credit, is an excellent compendium of papers.

It really warms my heart to look forward to the next conference on "Quantum Limits of Knowledge" planned in France in 2021. We live in remarkable times when progress in experimental physics allows philosophers and theoretical physicists to challenge established paradigms of quantum physics or to interpret those paradigms in a completely new way. Let us hope that this conference series will become a strong tradition and will continue producing useful insights into both physical and philosophical pictures of our world.

Publisher's Note Springer Nature remains neutral with regard to jurisdictional claims in published maps and institutional affiliations.

E. S. Polzik $(\varangle)$

The Niels Bohr Institute, Copenhagen, Denmark

e-mail: polzik@nbi.ku.dk 